\title{
Adolescent ovarian tumours: a gynecologist's dilemma
}

\section{Shreedevi Tanksale*, Kirti Bendre, Geeta Niyogi}

Department of Obstetrics \& Gynecology, K. J. Somaiya Medical College and Hospital, Mumbai, Maharashtra, India

Received: 26 April 2015

Revised: 05 May 2015

Accepted: 10 May 2015

*Correspondence:

Dr. Shreedevi Tanksale,

E-mail: shreedevitanksale@ hotmail.com

Copyright: (c) the author(s), publisher and licensee Medip Academy. This is an open-access article distributed under the terms of the Creative Commons Attribution Non-Commercial License, which permits unrestricted non-commercial use, distribution, and reproduction in any medium, provided the original work is properly cited.

\begin{abstract}
Background: Objective: To review the clinical presentation and outcome of ovarian tumours in children and adolescents upto 20 years of age, who presented at K. J. Somaiya Hospital and Medical research centre.

Methods: The study was carried out in the Ob/Gyn department at K. J. Somaiya Hospital and Medical research centre between 2006 and 2012 after approval from the ethical committee. The data of the patients regarding age, presentation, diagnosis, investigations, treatment, and outcome was reviewed and analysed.

Results: There were 32 patients between 13 and 20 years of age who presented with an ovarian tumour during the study period. Majority of the patients belonged to age group 17-19 years. The main presenting symptom was pain in abdomen in $21(65 \%)$ patients. Operative procedures included $18(56 \%)$ exploratory laparotomies and $14(44 \%)$ operative laparoscopies. Ovarian cystectomy was done in $23(71 \%)$ patients, unilateral oophorectomy in $3(9 \%)$ patients, bilateral oophorectomy with omentectomy in $1(3 \%)$ patient and salpingoophorectomy in 1 (3\%) patient. Histopathology reports showed 2 cases each of serous cystadenoma, mucinous cystadenoma and dermoid cyst and one case of dysgerminoma. Corpus lutueal cyst was most common cyst found on histopathology.

Conclusions: Early correct diagnosis of ovarian masses in young girls is important and can be reached by careful physical examination, imaging and tumour markers. Surgery should be as much as possible for fertility preservation. The treatment of malignant tumors would involve complete staging, resection of the tumor, postoperative chemotherapy when indicated, to give the patient a chance for future childbearing.
\end{abstract}

Keywords: Ovarian mass, Adolescent

\section{INTRODUCTION}

The diagnosis and management of ovarian masses in adolescents is a very challenging problem faced by gynaecologists. Ovarian masses in adolescents are uncommon and the actual incidence is difficult to estimate. An approximate incidence has been estimated as $0.0026 \%$, and malignant ovarian tumours comprise about $1 \%$ of all childhood cancers. ${ }^{1,2}$

Ovarian tumours occurring in adolescent age group have diverse presentations ranging from asymptomatic masses to acute abdominal pain. Benign and functional cysts are the most common ovarian lesions in childhood and adolescence. Although majority of the lesions are benign, it is important to identify notoriously lethal malignant lesions early for favourable prognosis. The conflict between surgical vs. conservative management in adolescent ovarian masses is challenging for the gynaecologist.

The risk of malignant neoplasms is lower among adolescents than among younger children. As the age increases, the incidence of epithelial tumours increases. Germ cell tumours are the most common tumours of the first decade of life but occur less frequently during adolescence. Mature cystic teratoma is the most frequent neoplastic tumor of children and adolescents, accounting 
for more than one half of ovarian neoplasms in women younger than 20 years of age. ${ }^{3}$

The current management protocols include radiological imaging and tumour markers. Except in cases of cancer, a more conservative management approach to these masses, with ovarian preservation is considered as a standard protocol. Operative procedures involving the ovary in young patients can result in compromise of future fertility, due to either removal of the ovary or the formation of adhesions. Laparoscopic approaches are used to adequately assess and resect ovarian tumours that are benign., However, the use of laparoscopy or minimally invasive techniques remains controversial in children with ovarian tumors. ${ }^{6}$

\section{METHODS}

This retrospective analysis was conducted at department of Obstetrics and Gynaecology at a tertiary teaching hospital in Mumbai.

Patients upto 21 years of age who presented with clinical or preoperative diagnosis of ovarian masses and operated upon for the same were included in this study. Data collected from the hospital medical records, after approval from hospital ethical committee, included age at the time of surgery, presenting complaints, USG findings, tumour markers, operative procedure, and histopathology report of tumours and outcome of the patients. The study was approved by the hospital ethical committee.

Statistical analysis was performed using unpaired t test.

\section{RESULTS}

Over a period of 6 years, 32 adolescent girls were operated upon for ovarian tumours at our hospital. Out of which, $24(75 \%)$ presented to the Obstetrics and Gynaecology department, 6 (18.75\%) were referred from Surgery department and $2(6.25 \%)$ from emergency room. Out of the 32 patients, 26 were unmarried and 6 were married. Majority of the patients belonged to age group 17-19 years. The mean age of presentation was 18.4 years (range 13-20 years). The youngest patient was that presented with abdominal mass was 13 years old. The most common presenting complaint was pain in abdomen in 21(65\%), followed by abdominal mass in 6 $(18 \%)$. Two $(6.2 \%)$ patients were incidentally found to have ovarian cysts during work up for infertility.

Table 1: Age at presentation $(n=32)$.

\begin{tabular}{|lll|}
\hline Age & Number & Percentage \\
\hline 13-16 years & 3 & 10 \\
\hline 17-19 years & 21 & 65 \\
\hline 20-21years & 8 & 25 \\
\hline
\end{tabular}

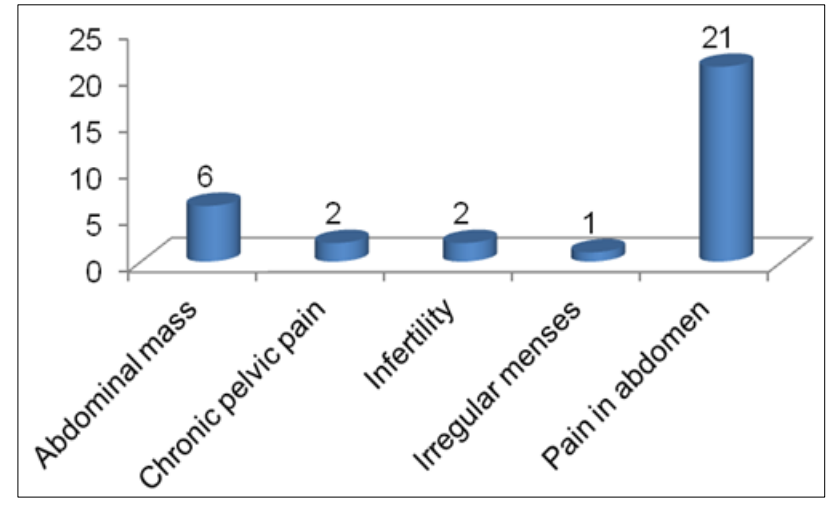

Figure 1: Complaint at presentation.

Ultrasound examination was done in all the patients to define size of lesion and its gross morphological nature. Out of 32 patients, 13 patients had tumour marker levels evaluated and only 7 had elevated levels of Serum LDH, out of which only two patients had malignant lesions. The other tumour markers were within normal limits. The rest of the patients did not agree to perform this investigation because of the cost.

Operative procedures included 18 (56\%) exploratory laparotomies and 14 (44\%) operative laparoscopies. Ovarian cystectomy was done in $23(71 \%)$ patients, unilateral oophorectomy in $3(9 \%)$ patients, bilateral oophorectomy with omentectomy in $1(3 \%)$ patient and salpingoophorectomy in $1(3 \%)$ patient.

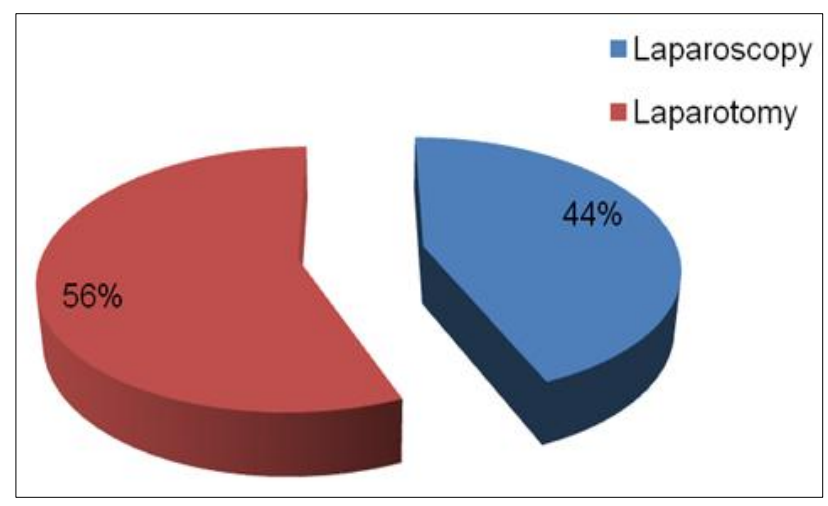

Figure 2: Exploratory laparotomy and operative laparoscopy at presentation.

Table 2: Surgical outcome $(n=32)$.

\begin{tabular}{|lll|}
\hline Outcome & Number & Percentage \\
\hline Cystectomy & 23 & 71 \\
\hline Unilateral oopherectomy & 3 & 9 \\
\hline $\begin{array}{l}\text { Bilateral oopherectomy with } \\
\text { omentectomy }\end{array}$ & 1 & 3 \\
\hline Unilateral salpingooopherectomy & 1 & 3 \\
\hline Aspiration with cystectomy & 2 & 7 \\
\hline Aspiration only & 2 & 7 \\
\hline
\end{tabular}


The majority of ovarian tumours were benign in this study with only two cases of malignant lesion detected. One of which was dysgerminoma and other was an immature dermoid cyst. On histopathological examination, 10 patients $(31.2 \%)$ had simple cysts and followed by corpus luteal cyst in 7 patients $(21.9 \%)$. Histopathology reports showed 2 cases each of serous cystadenoma, mucinous cystadenoma and dermoid cyst. There was one case of dysgerminoma detected which was malignant.

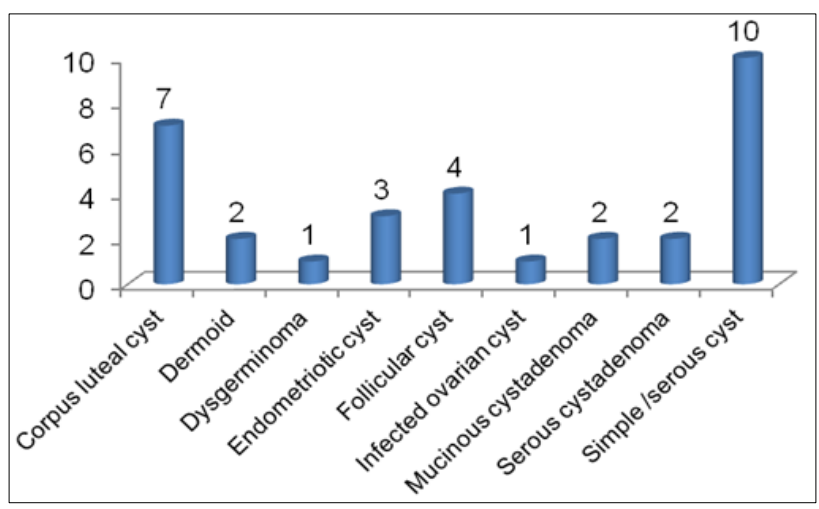

Figure 3: Ovarian tumours at presentation.

\section{DISCUSSION}

The ovary gives rise to a wide variety of tumours. The mass may range over a wide spectrum of pathology from benign to highly aggressive malignant tumours. Patients in early stages are usually asymptomatic. The main presenting symptoms being abdominal pain and mass. It is important to thoroughly examine the patient and reach a correct diagnosis. Ultrasound is an excellent, noninvasive, inexpensive and useful diagnostic tool. The ultrasound is well-established imaging technique in ovarian tumours having sensitivity of $89 \%$ and specificity of $73 \% .^{7}$ The most important tumour markers are CA125, AFP, $\beta$-HCG and LDH.Tumour markers are helpful but not reliable as a screening test.

In our study we had only 4 cases, 2 each of serous and mucinous cystadenomas. All were benign in nature. The frequency of germ cell tumours is reported to vary from $67 \%$ to $85 \% .^{8}$ In this study, the commonest tumour were epithelial (12.4\%) and closely followed by germ cell tumours $(9.3 \%)$. In other study, the commonest tumour were epithelial in origin $(70.83 \%)$ and germ cell tumour were second most common $(29.16 \%) .{ }^{9}$ Germ cell tumours accounted for $73.75 \%$, followed by epithelial tumours$22.5 \%$ in a study by Amatya A et al. Germ cells were seen to be three times more than epithelial tumours in younger age group. ${ }^{10}$

All malignant tumours in our study were germ cell tumours. In this study, $93.8 \%$ lesions were benign and $6.2 \%$ were malignant. Identical results with not a single case of epithelial ovarian carcinoma were found in a study. This study showed the preponderance of germ cell tumour and high percentages of malignancies within germ cell tumour in young children and adolescents. ${ }^{11}$ This study as well as studies which are included here for comparison have small sample size and are institution based, whereas most data of western world is taken from results of large population based studies 1 . This could be one cause of variation in results. Our study is also institution based and has small sample size. So the result obtained may or may not reflect the actual histological pattern and age distribution of ovarian tumors in young women.

For fertility preservation laparoscopic approach should be adopted where possible. This was demonstrated in the study by Pansky $\mathrm{M}$ et al., where premenarchal girls were managed by laparoscopic ovarian cystectomy. ${ }^{12,13}$ Benign ovarian cysts are amenable to cystectomy, allowing preservation of the remaining ovarian cortex. This often can be done, even with large cysts with little or no normal obvious ovarian tissue visible. There is risk of intraoperative spillage of cyst contents during manipulation with cystectomy, and this is problematic if the cyst exhibits borderline or frank malignancy, or if a dermoid spills with its risk of peritonitis and subsequent adhesion formation. However, recent literature for adult population suggests that laparoscopic excision is a safe procedure particularly when an endo-bag is used to remove the tumours from the abdomen. ${ }^{14-16}$ There appears to be no increase in recurrence rate as compared with laparotomy. This surgical approach depends upon the laparoscopic skills of the particular surgeon.

Gentle tissue handling, meticulous hemostasis and adhesion prevention strategies were adopted for fertility preservation. Surgical intervention is directed towards preservation of reproductive function. The incidence of malignant of tumours in adolescents is higher than in adults. Therefore, the detection of these lesions is worrisome to patients, her families, and gynaecologists. In this study most of the patients did not have regular follow-up due to the facts like complete cure, poverty, illiteracy, social background, relief of symptoms, may be the reason to avoid visiting hospitals.

\section{CONCLUSION}

Early correct diagnoses and preservation of fertility with should be the aim. There is need for bigger population studies with larger sample size. It is high time to address the issue in our community as patients not only belong to a tender age group, there are important questions related to their future fertility and quality of life as well. Support and sensitivity for the frightened girl and her family is essential as is high quality decision making by the gynaecologist.

\section{Funding: No funding sources \\ Conflict of interest: None declared}

Ethical approval: The study was approved by the hospital ethics committee 


\section{REFERENCES}

1. Skinner MA, Schlatter MG, Heifetz SA, Grosfeld JL. Ovarian neoplasms in children. Arch Surg. 1993;128:849.

2. Warner BW, Kuhn JC, Barr LL. Conservative management of large ovarian cysts in children: the value of serial pelvic ultrasonography. Surgery. 1992;112:749.

3. Kozlowski KJ. Ovarian masses. Adolesc Med. 1999;10:337-50.

4. Millingos S, Protopapas A, Drakakis P, Liapi A, Loutradis D, Rodolakis A, et al. Laparoscopic treatment of ovarian dermoid cysts: eleven years' experience. J Am Assoc Gynecol Laparosc. 2004;11:478.

5. Vaisbuch E, Dgani R, Ben-Arie A, Hagay Z. The role of laparoscopy in ovarian tumors of low malignant potential and early-stage ovarian cancer. Obstet Gynecol Surv. 2005;60:326.

6. Von Allmen D. Malignant lesions of the ovary in childhood. Semin Pediatr Surg. 2005;14:100.

7. DePriest PD, Varner E, Powell J, Fried A, Puls L, Higgins R. The efficacy of a sonographic morphology index in identifying ovarian cancer: a multi institutional investigation. Gynecol Oncol. 1994;55:174-8.

8. Breen J, Maxon WS. Ovarian tumours in childhood and adolescence. Clin Obstet Gynecol. 1977;20:60723.

9. Baloch S, Khaskheli M, Malik AM, Sheeba A, Khushk IA. Clinical spectrum and management of ovarian tumours in young girls upto 20 years of age. J Ayub Med Coll Abbottabad. 2008;20(4):14-7.

10. Amatya A, Rana G, Gurung L. Ovarian tumours in childhood and adolescents - our eight years experiences. Nepal J Obstet Gynaecol (NJOG). 2008 May-June;3(1):39-42.

11. Choudry A, Bangash N, Malik A, Choudry H. Adolescent ovarian tumors: a clinicopathlogical review of 15 cases. J Ayub Med Coll Abbottabad. 2008 Oct-Dec;20(4):18-21.

12. Pansky, M, Abargil, A, Dreazen, E, Golan A, Bukovsky I, Herman A. Conservative management of adnexal torsion in premenarchal girls. J Am Assoc Gynecol Laparosc. 2000;7:121-4.

13. Goldstein DP, deCholnoky C, Emans SJ, Leventhal JM. Laparoscopy in the diagnosis and management of pelvic pain in adolescents. $\mathrm{J}$ Reprod Med. 1980;24:251-6.

14. Rosen DM, Lam AM, Carlton MA, Cario GM. The safety of laparoscopic treatment for ovarian dermoid tumours. Aust NZ J Obstet Gynaecol. 1998;38:77-9.

15. Luxman D, Cohen JR, David MP. Laparoscopic conservative removal of ovarian dermoid cysts. J Am Assoc Gynecol Laparosc. 1996;3:409-11.

16. Lin P, Falcone T, Tulandi T. Excision of ovarian dermoid cysts by laparoscopy and by laparotomy. IS J Obstet Gynecol. 1995;173:769-71.

DOI: $10.18203 / 2320-1770 . i j \operatorname{rog} 20150102$

Cite this article as: Tanksale $\mathrm{S}$, Bendre $\mathrm{K}$, Niyogi $\mathrm{G}$.

Adolescent ovarian tumours: a gynecologist's dilemma. Int J Reprod Contracept Obstet Gynecol 2015;4:833-6. 